\title{
Mind the gap: Protolith vs. processing in establishing primitive achondrite redox conditions
}

\author{
T.J. MCCOY ${ }^{1}$, C.M. CORRIGAN ${ }^{1}$, T.L. DICKINSON ${ }^{2}$, G.K.
} BENEDIX $^{3}$, D.L. SCHRADER ${ }^{4}$ AND J. DAVIDSON ${ }^{4}$

${ }^{1}$ Dept. of Mineral Sciences, NMNH, Smithsonian Institution, Washington, DC USA (mccoyt@si.edu)

${ }^{2}$ Science Matters Consulting LLC, Washington, DC USA

${ }^{3}$ School of Earth and Planetary Sciences, Curtin University, Bentley, WA, Australia

${ }^{4}$ Center for Meteorite Studies, SESE, Arizona State

University, Tempe, AZ USA

The final state of planetary differentiation is a complex product of the precursor material and processes occurring during planetary melting. In the case of primitive achondrites, asteroidal melting was arrested before complete melting and differentiation. Nonetheless, these meteorites, including the acapulcoite-lodranite clan and silicates in IAB irons and closely-related stony winonaites, have redox conditions between the highly-reduced ( IW-5) enstatite chondrites and moderately reduced ( IW-1) [1,2] ordinary chondrites. Numerous authors have argued for reduction at or near the peak temperature during partial melting of acapulcoites and lodranites, suggesting that redox was largely a function of partial differentiation and requiring a redox gap in chondrites.

Grove Mountains (GRV) 020043 [3,4] is a type 4 chondrite, with abundant, well-delineated, pyroxene-rich chondrules, microcrystalline mesostasis, polysynthetically striated low-Ca pyroxene, and slightly heterogeneous plagioclase compositions. Similarities in mineralogy, mineral composition, and oxygen isotopic composition link GRV 020043 to the acapulcoite-lodranite clan. These features include a high low-Ca pyroxene to olivine ratio, high kamacite to taenite ratio, and relatively $\mathrm{FeO}$-poor mafic silicates (Fa10.3, Fs10.4) relative to ordinary chondrites, as well as $f \mathrm{O}_{2}$ (IW-2.2 to IW-3.5) typical of acapulcoites.

The mineralogy and mineral compositions of GRV 020043, despite modest thermal metamorphism, suggests that most features of acapulcoites previously attributed to reduction were, instead, inherited from the precursor chondrite. Thus, chondritic meteorites, from which asteroids and planets accreted, span the full range of $f \mathrm{O}_{2}$ from $\sim \mathrm{IW}-5$ (enstatite chondrites) to $\sim \mathrm{QFM}+3$ (CK chondrites) [1,2] without significant gaps.

[1] Righter and Neff (2007) Polar Science 1, 25-44. [2] Righter et al. (2016) Am. Min. 101, 1928-1942. [3] Li et al. (2018) GCA 242, 82-101. [4] McCoy et al. (2019) Geochemistry 79, 125536. 